\title{
COMUNICAÇÃO NO CONTEXTO \\ ORGANIZACIONAL: UM ESTUDO \\ DE CASO COM RELATÓRIOS \\ EMPRESARIAIS DA PETROBRÁS \\ SOBRE A DIVERSIDADE POR \\ ORIENTAÇÃO SEXUAL'
}

Communication within the organizational context: a

case study with Petrobrás business reports about sexual

diversity

\author{
Samira Loreto Edilberto Pompeu \\ samira.lep@gmail.com \\ Mestre em Administração de Empresas pela Escola de \\ Negócios da Pontifícia Universidade Católica do Rio de \\ Janeiro.
}

RESUMO: O objetivo da presente pesquisa foi de identificar e analisar o conteúdo dos documentos oficiais de uma empresa acerca da diversidade por orientação sexual. Como objetivos específicos, desejou-se analisar criticamente a comunicação do posicionamento de uma companhia mediante seus discursos em documentos públicos sobre a diversidade por orientação sexual, identificar possíveis inconsistências, ausências ou falta de homogeneidade em tais relatórios, bem como iniciativas positivas que podem servir como boas práticas. Foi escolhida a empresa Petrobrás por possuir um discurso formal em relação à diversidade sexual com base nos critérios do Corporate Equality Index da Human Rights Campaign - HRC. Foi realizada uma pesquisa de natureza qualitativa em seus documentos públicos como relatórios de sustentabilidade e o código de ética, tendo como método de tratamento de dados a análise de conteúdo. Foram constatadas inconsistências na comunicação por um lado, mas, por outro, alguns exemplos de boas práticas.

PALAVRAS-CHAVE: Orientação sexual. Comunicação corporativa. Sustentabilidade.

ABSTRACT: The aim of this research was to identify and analyze the contents of a company's official documents about sexual orientation diversity. As specific objectives, it desired to critically analyze the positioning communication of a company

1 Este artigo é reflexo de parte da Dissertação de Mestrado da autora, realizada no IAG/PUC-Rio (2015). Ele foi apresentado, em versão preliminar, no $5^{\circ}$ Seminário Interdisciplinar em Sociologia e Direito realizado pelo Programa de Pós-graduação de Sociologia e Direito - PPGDS da UFF em 2015.

52 | Revista Conhecimento em Ação, Rio de Janeiro, v. 1, n. 2, jul/dez. 2016 
through their speeches in public documents about the sexual orientation diversity, and to identify possible inconsistencies, absence or lack of homogeneity in such reports as well as positive initiatives that can serve as good practices. Petrobras was chosen because it has a formal speech regarding sexual diversity based on the criteria of the Corporate Equality Index / Human Rights Campaign - HRC. A qualitative research was conducted in its public documents as sustainability reports and the code of ethics, with the data processing method of content analysis. Inconsistencies were found in communication, but also, some examples of good practices.

KEYWORDS: Sexual orientation. Corporate communication. Sustainability.

\section{Introdução}

A responsabilidade social corporativa, a sustentabilidade e a ética são conceitos que de alguma forma possuem uma sobreposição, mas também algumas diferenças (CRISTENSEN et al., 2007). De um modo geral, a responsabilidade social corporativa (RSC) e a sustentabilidade corporativa referem-se às atividades de uma companhia que demonstrem preocupações com a inclusão social e ambiental nas operações de negócios e interações com os stakeholders (MARREWIJK, 2003). A ética, com sua origem no campo da filosofia, talvez seja um dos campos de estudo mais antigos, ainda que seja estudado até hoje (CRISTENSEN et al., 2007). Os referidos autores defendem que a ética ensinada nos cursos de pós-graduação em administração possui duas dimensões: o papel ético da companhia na sociedade - sua responsabilidade social corporativa e o papel da corporação em minimizar a destruição e maximizar a preservação de recursos para gerações futuras - sua gestão sustentável.

No que tange a questão da inclusão e exclusão social, um dos grupos mais marginalizados na sociedade brasileira é o das pessoas homossexuais, assim como dentro das empresas, em decorrência do heterossexismo e da homofobia presentes na sociedade (SIQUEIRA; ZAULI-FELLOWS, 2006).

Tendo em vista que relatórios e outros documentos oficiais de uma empresa podem representar uma boa fonte pública de análise do posicionamento de uma companhia em relação às questões sociais, foram considerados documentos como base para a pesquisa exploratória que pudessem conter o discurso de uma empresa acerca da diversidade por orientação sexual.

Assim, o objetivo da presente pesquisa foi de identificar e analisar o conteúdo 
dos documentos oficiais de uma empresa acerca da diversidade por orientação sexual. Como objetivos específicos, desejou-se analisar criticamente a comunicação do posicionamento da companhia mediante seus discursos em documentos sobre a diversidade por orientação sexual, identificar possíveis inconsistências, ausências ou falta de homogeneidade em tais relatórios, bem como iniciativas positivas que podem servir como boas práticas a serem adotadas por outras companhias que não sabem como lidar com tal diversidade.

De modo a alcançar o objetivo proposto, foram analisados documentos públicos disponíveis no site da empresa Petrobrás que mencionassem este tipo de diversidade. Foram encontrados os seguintes documentos para basear a análise: relatório de sustentabilidade (2009, 2010, 2011, 2012 e 2013), código de ética (em vigor desde 2006), programa Petrobrás cultural (2006/2007 e 2007/2008), memória cultural, relatório de transparência pública. Ainda que a pesquisa esteja baseada majoritariamente no conteúdo dos relatórios de sustentabilidade e no código de ética, alguns pontos presentes em outros relatórios auxiliaram a identificar outras iniciativas da companhia em relação a promoção da diversidade.

A pesquisa pode ser relevante tanto academicamente quanto para o mundo corporativo ao apresentar critérios, uma discussão mais aprofundada e prática do que representa o posicionamento público de uma companhia sobre a diversidade por orientação sexual, bem como ao realizar esta análise com base em um índice de igualdade corporativa de reconhecimento internacional.

\section{Comunicação corporativa e comunicação organizacional}

O amplo e, de certa forma, diverso campo da comunicação corporativa é caracterizado por uma mentalidade comum, uma determinada maneira de pensar e abordar a comunicação de uma organização, moldada por imagens e ideais de unidade, consistência, inteireza e totalidade (CHRISTENSEN; CORNELISSEN, 2011). Os autores afirmam que, muitas vezes, esta mentalidade corresponde às raízes etimológicas do adjetivo "corporativo": derivado do termo latino corpus, o termo corporativo sugere uma entidade coletiva unida em um corpo. Assim, classificar a comunicação como "corporativa”, significa invocar uma metáfora corporificada de unidade e totalidade (CHRISTENSEN; CORNELISSEN, 2011). 
Para os referidos autores, na prática, a visão de inteireza se desdobra em um objetivo de projetar uma imagem consistente e não ambígua do que a organização é e o que ela pretende representar. Mais do que buscar identidades diante de diferentes audiências ou permitir departamentos diferentes controlar suas comunicações com autonomia, a visão da comunicação corporativa contemporânea é de gerenciar todas as comunicações sob uma única bandeira (CHRISTENSEN; CORNELISSEN, 2011)

A comunicação integrada pode ser definida como a noção e prática de alinhar símbolos, mensagens, procedimentos e comportamentos de forma que a organização se comunique com clareza, consistência e continuidade dentro e através das fronteiras organizacionais (CHRISTENSEN; FIRAT; TORP, 2008). A noção de transparência também é valorizada nesta perspectiva bem como em estudos acerca das relações públicas, podendo-se dizer que no contexto das organizações modernas o termo transparência sugere abertura e permeabilidade em relação a informações, argumentos e ideias (CHRISTENSEN; LANGER, 2009). Espera-se ainda, segundo os mesmos, que as organizações contemporâneas sejam abertas no sentido de tornar disponível todo tipo de informação sobre suas operações e decisões.

Todavia, Christensen e Langer (2009) destacam que a informação disponível e a troca podem não constituir transparência real: enquanto a abertura é uma pré-condição para a transparência, ela não é suficiente por si só para assegurar o tipo de claridade e insight associados com a noção de transparência (CHRISTENSEN, 2002). Uma organização pode, por exemplo, ser muito aberta sobre suas decisões e documentos sem que essa abertura seja transformável em algo inteligível aos olhos da audiência externa (CHRISTENSEN; LANGER, 2009). Cabe lembrar também que ainda que haja uma suposta busca pela transparência, os meios de comunicação nunca são neutros (FROST, 1987).

Nesta perspectiva de comunicação, alega-se que sem coerência, integração ou consistência, as mensagens da organização podem ser mal-entendidas e suas audiências receberiam significados inconsistentes ou conflitantes que poderiam causar confusão ou falta de confiança em relação ao que a organização oferece ou apoia/ significa (CHRISTENSEN; CORNELISSEN, 2011). O que demanda, segundo os autores, no sentido da busca dessa consistência um olhar cuidadoso de jornalistas e da mídia crítica para evitar gaps, contradições e discrepâncias nas mensagens 
corporativas.

A crítica de Christenser e Cornelissen (2011) fazem a esse tipo de abordagem sobre a comunicação corporativa, é de que a organização não é nem um ator unitário e nem podem ser gerenciadas e controladas como tal. Alegam que as organizações devem ser vistas como coleções de indivíduos e atividades dispersas pelo mundo das quais as estratégias e ações coordenadas emergem. Assim, pode-se alegar que a comunicação interpessoal é a essência da organização, por afetar o que é dito, feito e por quem (WEICK, 1987).

Além disso, o foco na consistência das mensagens corporativas ignora as complexidades organizacionais e comportamentais da comunicação humana, sugerindo que a polifonia é essencial em contrapartida a tal homogeneidade (CHRISTENSEN; CORNELISSEN, 2011).

O entendimento da comunicação corporativa pode ser enriquecido mediante a ligação com o campo da comunicação organizacional, uma vez que a comunicação não é vista neste campo como um conduite por meio do qual as organizações simplesmente transmitem e amplificam suas autopercepções, mas como uma força ativa e constitutiva na construção das organizações (CHRISTENSEN; CORNELISSEN, 2011). Segundo os autores, nesta visão a comunicação é um processo dinâmico como o contexto social de fala e as interações com os outros afetando a construção de significado.

Neste sentido, a partir de uma visão que diverge da preocupação dos autores da comunicação corporativa com unidade, integração e controle das mensagens, tem-se a visão de comunicação organizacional pautada no princípio de que a comunicação constitui a organização, ou a CCO - Communicative Constitution of Organizations (PUTNAM; NICOTERA, 2009; 2010; CHRISTENSEN; CORNELISSEN, 2011).

A constituição comunicativa da organização (CCO) é um conjunto de perspectivas que fundamentam o papel da comunicação na ontologia da organização (PUTNAM; NICOTERA, 2010). De acordo com Putnam e Nicotera (2010), os acadêmicos da CCO não reduzem a organização à interação social, linguagem ou discurso, nem reivindicam a equivalência entre comunicação e organização. Em vez disso, almejam tratar quão complexo o processo de comunicação constitui tanto a organização quanto o processo de organizar (organizing) e como estes processos e resultados moldam a comunicação (PUTNAM; NICOTERA, 2010). Embora exis- 
tam diversas abordagens para a constituição comunicativa da organização, há um ponto de convergência entre eles já que aceitam a mesma ênfase no efeito formativo da linguagem e do discurso em geral e do discurso organizacional, em particular, adquirem relevância nesta perspectiva na criação do senso coletivo e coordenação social (CHRISTENSEN; CORNELISSEN, 2011).

\section{Aspectos metodológicos: critérios para escolha da empresa e método de análise de dados}

Para a realização da presente pesquisa, foi necessário escolher uma empresa que de alguma forma abordasse em seus documentos públicos a questão da diversidade sexual - tema que muitas vezes é invisibilizado no ambiente corporativo. Assim, foi escolhida uma empresa segundo os critérios do selo da fundação norte-americana Human Rights Campaign - HRC - organização de direitos civis que trabalha para alcançar a igualdade para pessoas lésbicas, gays, bissexuais e transgêneras (HRC, 2015a). Dentro do programa de igualdade no local de trabalho, a fundação HRC desenvolveu o Corporate Equality Index - CEI. Trata-se de um relatório de melhores práticas em relação à diversidade LGBT e inclusão entre as maiores companhias nos Estados Unidos (HRC, 2015b). O CEI representa uma ferramenta altamente influente em relação à justiça no trabalho de pessoas LGBTs no referido país (HRC, 2015b).

Tais critérios internacionais foram necessários uma vez que no Brasil não existe nenhum órgão ou política de certificação de empresas que apresentem boas práticas com relação a orientação sexual de seus trabalhadores. Além disso, não se tem notícia de outro selo no âmbito internacional que pudesse ser utilizado como critério. De acordo com o trabalho de Mecchi (2006), o Corporate Equality Index é usado muitas vezes pelas próprias empresas como fonte de aprendizado para lidar com o assunto da diversidade sexual em seus ambientes organizacionais. O CEI possui 4 critérios que, se atingidos, oferecem uma pontuação para a empresa, até chegar a 100 - quando ela ganha o selo best places to work for LGBT equality - 100\% corporate equality index.

Os critérios usados pelo CEI são: (1a) proibição da discriminação com base na orientação sexual; (1b) proibição da discriminação com base na identidade ou 
expressão de gênero; (2a) a empresa oferece seguro de saúde / seguro médico para parceiros(as) de funcionários(as) homo/ bissexuais; (2b) os(as) parceiros(as) de pessoas homossexuais tem direito a receber os mesmos benefícios que os parceiros(as) de pessoas heterossexuais; (2c) oferece cobertura de seguro de saúde para pessoas transgêneras; (3a) possui programa de competências organizacionais para toda a empresa que inclua as questões LGBTs; (3b) tem custeada pela entidade patronal do empregado algum tipo de Conselho de Diversidade; (4) Apoia a comunidade LGBT com ações externas. A empresa terá sua pontuação deduzida caso haja alguma marca anti LGBT em seus registros recentes (HRC, 2013).

O objetivo da presente pesquisa foi de identificar e analisar o conteúdo dos documentos oficiais de uma empresa acerca da diversidade por orientação sexual. Como objetivos específicos, desejou-se analisar criticamente a comunicação do posicionamento de uma companhia mediante seus discursos em documentos públicos sobre a diversidade por orientação sexual, identificar possíveis inconsistências, ausências ou falta de homogeneidade em tais relatórios, bem como iniciativas positivas que podem servir como boas práticas.

Para alcançar o objetivo proposto, foi realizada uma pesquisa de natureza qualitativa, tendo como método de tratamento de dados a análise de conteúdo. A análise de conteúdo pode ser definida como "um conjunto de técnicas de análise das comunicações, que utiliza procedimentos sistemáticos e objetivos de descrição do conteúdo das mensagens" (BARDIN, 1977, p. 38). Sobre intenção do método, pode-se dizer que é: "a inferência de conhecimentos relativos às condições de produção (ou, eventualmente, de recepção), inferência esta que recorre a indicadores (quantitativos ou não)" (BARDIN, 1977, p. 38).

A pesquisa em relatórios foi realizada mediante a leitura dos documentos do código de ética (em vigor desde 2006) e em cinco relatórios de sustentabilidade (dos anos de 2009, 2010, 2011, 2012 e 2013) disponíveis no site da empresa, em relatórios referentes ao programa cultural da companhia, em um documento de licitações e contratos disponível no site e no site da memória cultural da companhia (importante principalmente para identificar as ações de apoio externo). A seguir, foram extraídos os excertos do referido material que mencionassem diretamente questões ligadas ao tema da pesquisa, contendo termos como "orientação sexual", "diversidade sexual”, "homofobia”, "gay”, "lésbica”, "LGBT”. A análise do conteúdo 
do material foi norteada pelas três categorias estabelecidas a priori que nortearam também as perguntas elaboradas no roteiro de entrevista para os funcionários mencionadas na metodologia.

No que diz respeito ao relatório de sustentabilidade, não foram verificados esses temos em relatórios anteriores ao ano de 2011 já que em 2009 (PETROBRÁS, 2010) e em 2010 (PETROBRÁS, 2011a) não há nenhuma referência a estas questões que parecem surgir publicamente apenas em 2011 (PETROBRÁS, 2012). Na busca por informações que contemplassem a questão LGBT por parte da companhia em seu site, também foram encontrados outros documentos públicos que foram considerados na presente pesquisa por apresentarem informações relevantes.

\section{Resultados alcançados}

Esta seção foi dedicada aos resultados da parte exploratória da pesquisa, ou seja, a análise de conteúdo dos documentos oficiais da empresa acerca da diversidade por orientação sexual. Ela está dividida em três grades eixos ou categorias. A saber: (categoria 1) políticas organizacionais de diversidade sexual - presenças e ausências; (categoria 2) relações interpessoais e orientação sexual no ambiente de trabalho; (categoria 3) sociedade, orientação sexual e homofobia. Vale lembrar que cada categoria possui suas subdivisões, de forma a aprofundar a análise de conteúdo.

De forma geral, pode-se dizer que a primeira categoria aborda o tema da pesquisa de um ponto de vista mais macro, da perspectiva de um nível organizacional/ institucional, de suas políticas ou a ausência delas. Foram agrupadas questões ligadas à área de Recursos Humanos, como a política de benefícios. A segunda categoria apresenta uma análise de um ponto de vista mais micro (níveis tático e operacional), ao analisar as relações entre as pessoas - relevante já que aí podem surgir conflitos relacionados à discriminação homofóbica no cotidiano da prática empresarial. Por último, a terceira categoria estabelece um elo entre a empresa analisada e sua relação com a sociedade, já que é inerente à responsabilidade social a preocupação com ações que extrapolem os muros da realidade interna da empresa e conecte-a com a sociedade de maneira mais ampla.

Vale destacar que os critérios pontuados pelo Corporate Equality Index - CEI, abordados no tópico anterior sobre os aspectos metodológicos, foram fundamen- 
tais para, além de servirem como critérios de escolha da empresa deste estudo de caso, basear e nortear a realização da presente análise de conteúdo, como poderá ser visto a seguir.

\subsection{Categoria 1: políticas organizacionais de diversidade sexual-presenças e ausências}

Esta categoria teve por objetivo identificar quais são as políticas formais da organização em relação à diversidade sexual a partir do que é comunicado em seus documentos oficiais e formais. Duas categorias foram encontradas na análise dos documentos que convergem com as utilizadas pelo Corporate Equality Index para avaliar o tratamento dado pelas empresas aos funcionários LGBTs, a saber: a proibição da discriminação que inclui a orientação sexual e a política de benefícios. Este tópico traz também uma terceira categoria que emergiu a partir da leitura dos documentos - "a ausência premiada" - uma vez que nem sempre a questão LGBT esteve presente nas políticas da companhia embora ainda assim recebesse diversos prêmios.

\subsubsection{Proibição de discriminação que inclui a orientação sexual}

A proibição de discriminação por orientação sexual está presente tanto no código de ética quanto no relatório de sustentabilidade. A divulgação desta proibição de discriminação é fundamental, uma vez que muitas empresas apenas falam de forma genérica a proibição de discriminação, não especificando que grupos são contemplados ou, se especificam, tratam de grupos mais tradicionalmente abordados em questões de diversidade (como mulheres, negros) deixando de lado as minorias sexuais.

Trata-se aqui do primeiro item que seria pontuado de acordo com os critérios do Corporate Equality Index (critério 1a) a proibição da empresa de discriminação por orientação sexual. Não houve qualquer menção pública em relatórios oficiais sobre proibição de discriminação com base na identidade de gênero que seria o critério $1 \mathrm{~b}$ do mesmo índice e incluiria as pessoas transgêneras (o que pode ser uma possibilidade de melhoria). 
No código de ética pesquisado, foram encontradas referências a questões relativas ao tema desta pesquisa em dois momentos. O primeiro no terceiro princípio dos doze princípios éticos elencados pela companhia:

A honestidade, a integridade, a justiça, a equidade, a verdade, a coerência entre o discurso e a prática referenciam as relações do Sistema [nome da empresa] com pessoas e instituições, e se manifestam no respeito às diferenças e diversidades de condição étnica, religiosa, social, cultural, linguística, política, estética, etária, física, mental e psíquica, de gênero, de orientação sexual e outras (PETROBRÁS, [2006], p. 7).

A segunda menção ocorre em outra sessão, sobre os compromissos com a conduta da empresa nas relações com os empregados:

respeitar e promover a diversidade e combater todas as formas de preconceito e discriminação, por meio de política transparente de admissão, treinamento, promoção na carreira, ascensão a cargos e demissão. Nenhum empregado ou potencial empregado receberá tratamento discriminatório em consequência de sua raça, cor de pele, origem étnica, nacionalidade, posição social, idade, religião, gênero, orientação sexual, estética pessoal, condição física, mental ou psíquica, estado civil, opinião, convicção política, ou qualquer outro fator de diferenciação individual (PETROBRÁS, [2006], p. 18).

Por sua vez, no Relatório de sustentabilidade 2012 há duas referências a questões de orientação sexual (uma sobre casos de discriminação levados a ouvidoria que será tratado no tópico correspondente e outra sobre a proibição de discriminação que será tratada aqui). A segunda referência encontra-se no tópico Diversidade do Público Interno:

Oferecemos igualdade de oportunidades de trabalho a todos os nossos empregados. Não toleramos qualquer tipo de discriminação, seja de raça, sexo, crença, orientação sexual ou qualquer tipo de deficiência. A diversidade é um valor em nossas políticas, práticas e procedimentos, 
que respeitam a diversidade de culturas, conhecimentos e aptidões (PETROBRÁS, 2013, p.128).

No relatório de sustentabilidade de 2013, só há menção a questões relativas a orientação sexual em dois momentos: uma ligada a proibição de discriminação que será tratado aqui e outra ligada a ouvidoria que será tratada em tópico correspondente.

Assim, no quadro de exigências contratuais para contratar os fornecedores, é no critério "direitos humanos" em que há a primeira menção a questões relativas a orientação sexual do relatório:

Autodeclarar, no Termo de Responsabilidade Social, que sua empresa coíbe quaisquer práticas de discriminação por raça, classe social, nacionalidade, religião, deficiência, sexo, orientação sexual, associação sindical ou política (PETROBRÁS, 2014, p. 34).

Ou seja, ao menos publicamente a companhia inclui a proibição da discriminação por orientação sexual nas práticas de trabalho, como exigência contratual para contratar fornecedores, como compromisso de conduta e como forma de diferença que deve ser respeitada. Todas essas inclusões em relatórios oficiais públicos podem ser vistas como boas práticas da companhia em que outras empresas que em momento algum citam a orientação sexual em seus relatórios ou mesmo sites podem se inspirar como uma iniciativa positiva para os trabalhadores homossexuais e bissexuais. No entanto, vale ressaltar que apenas a presença de tais questões em relatórios não significa a não ocorrência da discriminação homofóbica no dia a dia do trabalho.

\subsubsection{Política de benefícios}

A extensão de benefícios para parceiros do mesmo sexo também está presente nos critérios pontuados pelo Corporate Equality Index (2a, 2b, 2c).

Como poderá ser visto a seguir, o critério 2a que está ligado ao plano de saúde está presente nos relatórios. $\mathrm{O} 2 \mathrm{~b}$, se há paridade para outros benefícios também por conta dos benefícios previdenciários. Não se pode afirmar se este critério está 
contemplado em sua totalidade, pois não se sabe se são todos os benefícios que são estendidos para parceiros de homossexuais tanto quanto de heterossexuais. $\mathrm{O}$ $2 c$ - seguro saúde para indivíduos transgêneros - sequer é citado (representando outra possibilidade de melhoria).

No relatório de sustentabilidade do ano de 2011 há a primeira menção a questões relativas a orientação sexual na sessão sobre "Diversidade e equidade de gênero", sub tópico "pactos e iniciativas":

A companhia é pioneira em iniciativas de respeito à diversidade e reconhece, desde 2007, o direito a benefícios previdenciários para parceiros do mesmo sexo, incluindo a cobertura do programa de Assistência Multidisciplinar de Saúde. Atualmente, 111 funcionários (63 homens e 48 mulheres) usufruem do direito de ter seus companheiros no plano de saúde. Essas ações são acompanhadas pela Subcomissão de Diversidade da Petrobrás (PETROBRÁS, 2012, p. 76).

Nos relatórios dos anos posteriores não há mais referências sobre quantos empregados homossexuais (homens e mulheres) estão usufruindo desse tipo de benefício do plano de saúde.

De forma geral, não se percebe uma consistência na comunicação ou na existência das ações ligadas a diversidade sexual às menções que são feitas ao longo dos anos e em diversos relatórios. Por exemplo, alguma menção é feita a questões de orientação sexual nos relatórios de sustentabilidade a partir de 2011 e nos anos anteriores nada é mencionado. Todavia, a proibição de discriminação está presente no código de ética - que não é um documento lançado anualmente - mas que foi elaborado em 2006. Neste período entre o código de ética de 2006 e a aparição no relatório de 2011 há a notícia neste mesmo relatório de uma iniciativa em 2007 que, a partir de então, houve o reconhecimento de benefícios para parceiros do mesmo.

\subsubsection{A ausência premiada}

Pode-se verificar, a partir da leitura dos documentos, que nem sempre a questão LGBT esteve presente nos relatórios da empresa seja em forma de política oficial ou mesmo qualquer outra menção referente ao tema. No relatório de sustentabilidade 
do ano de 2009, por exemplo, não há qualquer menção às questões da diversidade sexual (PETROBRÁS, 2010). Existem apenas outras formas de diversidade presentes claramente no relatório como de gênero e racial.

Estranhamente, a ausência de questões ligadas especificamente ao segmento LGBT não implicou na perda de prêmios para a empresa. Uma vez que no fim do relatório há uma sessão "Reconhecimentos, prêmios e certificações" em que a empresa lista os 20 títulos que recebeu (como Top social 2009, Marcas de destaque em responsabilidade social 2009, Melhores e Maiores da Exame dentre outras). Relativiza-se aqui para quem são esses prêmios ou o que se premia, já que a empresa até então, pelo menos, nada divulgou sobre alguma possível iniciativa relativa às minorias sexuais.

De forma análoga ao ano anterior, no Relatório de Sustentabilidade 2010 (PETROBRÁS, 2011a) também não houve nenhum termo referente a orientação sexual, diversidade sexual, homofobia, homossexualidade, gay, lésbica ou LGBT. Ainda assim há a presença dos tópicos "Diversidade e equidade de gênero" em que mostra o resultado do censo da empresa com relação a diversidade racial (apresentando dados como por exemplo o número de empregados brancos, pardos, pretos, amarelos, indígenas; o número de empregados por gênero e faixa etária bem como a proporção salário base entre homens e mulheres por categoria funcional. Também existe a sessão "Direitos Humanos" e o tópico "promoção da cidadania”, em que também seria um tópico de potencial aproximação a questões de respeito a diversidade sexual, que, no entanto, não faz nenhuma referência a esta questão (PETROBRÁS, 2011a).

\subsection{Categoria 2: relações interpessoais e orientação sexual no ambiente de trabalho}

Enquanto o tópico anterior abordou as políticas de diversidade por orientação sexual, esta sessão está voltada ao tema do discurso da homofobia também presente no problema de pesquisa. Afinal, acredita-se que a discriminação por orientação sexual esteja seja mais perceptível nas relações entre os funcionários em seu cotidiano de trabalho. 


\subsubsection{Discriminação por orientação sexual presente na ouvidoria}

No Relatório de sustentabilidade 2012 há a o início da ação da empresa de incluir a discriminação por orientação sexual nas questões ligadas à ouvidoria. Ela se encontra na sessão "Recebimento de Manifestações" como pode ser visto a seguir:

Em 2012, nossa Ouvidoria Geral registrou 97 casos relativos a direitos humanos. Destes, 59 são relativos à violência psicológica no trabalho, sendo que, após apuração e tratamento, apenas um foi assim configurado e as medidas cabíveis foram tomadas. Dos demais, três estão em análise, 42 foram arquivados por não apresentarem dados suficientes para início do tratamento, e 13 não se configuraram procedentes. De acordo com a taxonomia prevista pelo Sistema de Tratamento de Demandas da Ouvidoria Geral, foram registradas 38 demandas que se referem a ocorrências de discriminação por gênero, orientação sexual e cor da pele/raça. Em decorrência destes registros, as áreas investiram em ampliação da discussão sobre os temas, a fim de esclarecer a força de trabalho e prevenir futuras ocorrências (PETROBRÁS, 2013, p. 50).

Percebe-se que dos 97 casos recebidos em 2012 poucos foram julgados procedentes. Por exemplo, dos 59 casos de violência psicológica no trabalho apenas 1 deles gerou uma resposta da empresa que, pelo menos para o público externo não especifica qual foi por dizer que foram tomadas "medidas cabíveis". A justificativa falta de dados para o início do tratamento também gerou o arquivamento de 42 casos pertencentes a esses 59 de violência psicológica. Se por um lado entende-se a importância de dados mais concretos para apurar uma situação com justiça, por outro imagina-se que um trabalhador vítima de violência psicológica no trabalho também possua dificuldade para, além de suportar a violência, recorrer a algum mecanismo de comprovação desta ou prevê-la.

Imagina-se que a lógica usada pela ouvidoria da companhia para julgar os casos de violência psicológica como procedentes ou não seja a mesma para os casos de discriminações. Dos 38 casos registrados de discriminação não se sabe quantas são de cada tipo (por conta do machismo, homofobia ou racismo respectivamente). 
Além disso, não fica claro o que efetivamente foi feito para resolver a questão. Parece também não ter havido nenhuma medida efetiva que corrigisse o fato discriminatório (punisse, por exemplo) ocorrido. Apenas a inclusão de discussões para que o já ocorrido não voltasse a acontecer novamente. Ou seja, os agressores permaneceram ilesos, apenas ganharam alguns momentos de discussões sobre discriminação.

Uma medida diferente do relatado em 2012 parece ter sido tomada a seguir. A orientação sexual está presente em questões ligadas a ouvidoria no ano seguinte, Relatório de sustentabilidade 2013 na sessão "diversidade e equidade de gênero":

Recebemos 13 manifestações relativas a casos de discriminação. Destas, cinco permanecem em tratamento e oito foram concluídas, dentre as quais três foram identificadas como procedentes. Em um caso, houve afastamento do empregado de empresa prestadora de serviço por ter agido com preconceito de gênero. Em outro, foi feita advertência verbal e orientação para que não se repetissem comentários ou comportamentos preconceituosos em relação à orientação sexual. Também promovemos encontro entre os envolvidos em episódio de preconceito racial, com ação educativa para que não houvesse novas ocorrências. Consideramos como discriminação tudo o que envolve comportamentos preconceituosos que possam levar a atitudes de exclusão (PETROBRÁS, 2014, p.45).

Percebe-se um avanço no ano de 2013 em relação ao de 2012 no que diz respeito às ações de punição. Se em 2012 a resposta da empresa foi apenas de ampliar a discussão sobre a discriminação, em 2013 ao menos houve uma advertência verbal condenando comportamentos homofóbicos.

Cabe observar outras questões acerca da comunicação deste fato ao observar o relatório de 2013. Na mesma página em que há este relato, há dados relativos a outras formas de diversidade com tabelas relativas a questões raciais e de gênero. No primeiro caso, há o percentual de empregados brancos, pardos, pretos, amarelos, indígenas em relação ao total de empregados. No segundo, há dados sobre o crescimento do número de mulheres no corpo funcional da empresa, bem como em carreiras de predomínio histórico masculino, a quantidade de mulheres que 
ocupam cargos de liderança e a comparação de salário base e remuneração entre homens e mulheres de acordo com nível de escolaridade (médio ou superior) e tipo de função (gratificada ou não). O que chama a atenção, na verdade, é o silêncio com relação a questões LGBTs que aparentemente, não possuem nenhum dado oficial a ser divulgado como os referidos outros tipos de diversidade. Não se sabe o quanto ganham tais empregados em comparação a empregados heterossexuais e também não é divulgado (ou não se sabe) nem quantos empregados LGBTs existem na empresa o que poderia ser um dado importante para a adoção de políticas específicas para este segmento.

Assim, no que diz respeito às relações interpessoais e a orientação sexual no ambiente de trabalho desta empresa, segundo os relatórios pode-se perceber a ocorrência da discriminação homofóbica entre outras formas de discriminação e de violência psicológica. A companhia não fornece maiores detalhes sobre que tipo de discriminação por orientação sexual é esta (se é por conta do humor preconceituoso, violência verbal, assédio moral, entre outros), e reconhece sua existência a partir de 2012, prosseguindo em 2013. Acredita-se que, dado o porte da companhia, outros casos de discriminação homofóbica tenham acontecido em anos anteriores mas não divulgados. É importante que a empresa divulgue casos relativos a discriminação homofóbica para que outros funcionários que se sintam de alguma forma atingidos saibam que existe o canal da ouvidoria para recorrer.

\subsection{Categoria 3: sociedade, orientação sexual e homofobia}

Foi realizada uma análise em separado das ações externas já que estas podem contribuir para a redução da homofobia e pouco comum por parte das empresas brasileiras. Além disso, ações externas que contribuam com a comunidade LGBT são ponto de pontuação do Corporate Equality Index em relação aos melhores locais para LGBTs trabalharem. O índice pontua parcialmente dependendo da quantidade de iniciativas.

\subsubsection{Ação externa de apoio à parada do orgulho LGBT}

A companhia divulgou no site, em "contrato de serviços" (PETROBRÁS, 2011b), 
entre outros diversos financiamentos a eventos, institutos e iniciativas o patrocínio do valor de $\mathrm{R} \$ 150.000,00$ à $16^{\text {a }}$ parada do orgulho LGBT do Rio (que ocorreu no ano de 2011). O valor foi doado ao grupo arco-íris de conscientização - ONG responsável pela organização do evento. Cabe lembrar que a companhia movimenta altos valores em contrato de serviços, tendo como valor total dos serviços contratados pela companhia de $\mathrm{R} \$ 63.378 .359 .714,53$ naquele ano.

Em outro documento, no relatório de sustentabilidade do ano de 2011, há menção a questões relativas a orientação sexual na sessão sobre "Diversidade e equidade de gênero", sub tópico "pactos e iniciativas":

Novamente patrocinamos a Parada do Orgulho LGBT (Lésbicas, Gays, Bissexuais e Transgêneros), o maior evento cultural de afirmação da diversidade na cidade de São Paulo (PETROBRÁS, 2012, p. 76).

Embora aqui se use o termo "novamente", que se refere a uma repetição, é de se estranhar que não houve qualquer referência a iniciativa do patrocínio da parada do orgulho LGBT no relatório do ano anterior, de 2010. Nos relatórios de sustentabilidade dos anos subsequentes (2012 e 2013) não se encontram mais menções ao patrocínio da parada LGBT. Não se sabe se não ocorreu o patrocínio ou se a empresa, por algum motivo, não achou relevante divulgá-lo.

\subsubsection{Apoio a filmes e festivais}

Além do patrocínio da parada do orgulho LGBT tanto do Rio de Janeiro quanto de São Paulo, a companhia também realizou o apoio a festivais e produção de filmes. Na edição do seu programa cultural de 2006/2007, no que tange ao cinema (produção de filmes de longa-metragem) a empresa contemplou os projetos de dois filmes com temática homossexual: "Mano" e "Hoje”. Ao todo, neste período foram contemplados 30 projetos de filmes diversos (PETROBRÁS, 2006).

No que tange o auxílio financeiro a festivais de cinema, no período de 2007/2008 a empresa contemplou o $16^{\circ}$ Festival Mix Brasil de Cinema e Vídeo da Diversidade Sexual (PETROBRÁS, 2007). Segundo informações contidas no relatório dos programas contemplados do programa cultural da empresa 2007/2008: 
O Festival Mix Brasil de Cinema e Vídeo da Diversidade Sexual, criado em 1993, rapidamente se tornou referência política e cultural de questões relacionadas à diversidade sexual. Com suas origens ligadas ao New York Gay and Lesbian Experimental Film Festival, o evento teve enorme impacto junto ao público e na mídia por exibir filmes e vídeos que abordavam sob diferentes ângulos e por meio de linguagens inovadoras a questão da diversidade sexual. O festival conta com oficina audiovisual, debates, mostra competitiva e retrospectiva de filmes brasileiros com a temática da diversidade sexual e ações de difusão de filmes brasileiros no exterior (PETROBRÁS, 2007, p. 2).

Além deste, outros 17 festivais de outros temas também foram contemplados no mesmo período (PETROBRÁS, 2007). No site da memória cultural da companhia (PETROBRÁS, 2009), há a presença do patrocínio ao festival Mix também nos anos de 2005 e 2003.

Dessa forma, considerou-se como sendo iniciativas importantes os apoios financeiros a eventos ligados a questões LGBTs como a parada do orgulho LGBT, projetos de filmes com a temática homossexual e Festival Mix Brasil de Cinema e Vídeo da Diversidade Sexual fornecidos pela empresa. Se a homofobia está presente na sociedade e a empresa recebe funcionários desta mesma sociedade que discrimina pessoas por conta da orientação sexual, a empresa também pode atuar para reduzir esta discriminação com ações externas que permitam a visibilidade da questão LGBT. Serve também como exemplo de boas práticas para outras empresas que desejem realizar ações de responsabilidade social que muitas vezes se limitam aos mesmos poucos grupos escolhidos.

\section{Considerações finais}

A presente pesquisa almejou identificar e analisar o conteúdo dos documentos oficiais de uma empresa acerca da diversidade por orientação sexual. Mais especificamente, desejou-se aqui analisar criticamente a comunicação do posicionamento da Petrobrás - mediante seus discursos em documentos públicos - sobre a diversidade por orientação sexual, identificar possíveis inconsistências, ausências ou falta 
de homogeneidade em tais relatórios, assim como iniciativas positivas que possam servir como boas práticas para outras organizações.

Portanto, ao analisar os documentos públicos da Petrobrás foram encontradas três grandes categorias de análise que puderam ser desdobradas em subcategorias: a categoria (1) "políticas organizacionais de diversidade sexual" abarca as subcategorias: 1. Proibição de discriminação que inclui a orientação sexual; 2. Política de benefícios 3. A ausência premiada. Por sua vez a categoria (2) "relações interpessoais e orientação sexual no ambiente de trabalho" contou apenas com uma subcategoria: 1. Discriminação por orientação sexual presente na ouvidoria. Por último, a categoria (3) "sociedade, orientação sexual e homofobia" abrangeu: 1. Ação externa de apoio à parada do orgulho LGBT; 2. Apoio a filmes e festivais.

De forma geral, mesmo nos anos em que há alguma menção a questões ligadas a orientação sexual em um ou dois parágrafos dentro de todo o relatório, chama atenção o pouco espaço que é dedicado a tal tema dada a grande dimensão dos relatórios de sustentabilidade - que possuem de 73 páginas (relatório de 2013) a 193 páginas (relatório de 2010).

A partir do que é comunicado publicamente, ao menos por parte dos relatórios de sustentabilidade, não se pode inferir a existência de uma política clara para questões LGBTs e comum às diversas edições dos relatórios ao longo dos documentos disponíveis no site da companhia. O que se pode perceber são iniciativas pontuais, diversas umas das outras sem grande comunicação em seus documentos públicos de sua continuidade (o que não quer dizer que, necessariamente, não existam).

Algumas propostas de melhoria podem ser relevantes na comunicação das práticas da Petrobrás que podem servir de inspiração para outras empresas. Para uma maior clareza na comunicação, sugere-se que as iniciativas pontuais presentes nos relatórios de sustentabilidade estejam presentes em outros anos - ainda que a iniciativa tenha sido descontinuada, poder-se-ia explicar o porquê. Por exemplo, da mesma forma que no relatório de 2011 (PETROBRÁS, 2012) a companhia menciona quantos(as) funcionários(as) homossexuais estão usufruindo do benefício do plano de saúde, nos relatórios posteriores a empresa poderia apurar e continuar a divulgar este tipo de informação, de modo a verificar se houve aumento, diminuição ou se o número se manteve em relação ao ano passado. É interessante também analisar quantos(as) funcionários(as) solicitam o benefício para companhia para 
comparar com o número total de funcionários que ela possui e se este número está próximo à proporção de homossexuais na sociedade. Ainda que nem todos os(as) homossexuais estejam com parceiros(as), considera-se aqui 111 funcionários(as) homossexuais usufruindo de tal benefício em uma empresa com 86.111 funcionários(as) um número bastante reduzido.

Outro exemplo que se sugere comunicar em outros anos é o caso do relatório de sustentabilidade de 2012 (PETROBRÁS, 2013) em que a empresa comunica que oferece igualdade de trabalho aos empregados e não tolera discriminação, inclusive por orientação sexual. Este comunicado é importante para que os funcionários de informem, serve como reforço ao código de ética e como respaldo para possíveis práticas discriminatórias que possam ocorrer dentro da companhia, por isto sugere-se que não fique restrito a ser divulgado em apenas um ano de relatório de sustentabilidade.

De forma semelhante, outro comunicado pontual, porém muito importante como posicionamento contra a discriminação por orientação sexual foi o citado no relatório de sustentabilidade de 2013 (PETROBRÁS, 2014) em que a empresa menciona que uma de suas exigências contratuais para contratar fornecedores é que a empresa fornecedora deva declarar que proíbe práticas de discriminação por orientação sexual. Como esta questão apareceu apenas em 2013 não se sabe se a empresa já possuía esta prática e não comunicou ou só em 2013 é que incluiu este critério de contratação de serviços externos. De qualquer forma, considera-se uma iniciativa importante caso ocorra de fato - pois estimula a proibição da discriminação por orientação sexual para além das fronteiras da organização, incluindo seus stakeholders, que possuem interesse financeiro em serem contratados. Sugere-se aqui que a empresa mantenha este critério de contratação como estímulo ao respeito à diversidade sexual.

Sobre a atuação da ouvidoria comunicada pelos documentos, embora considere-se sempre importantes ações de discutir e tornar visível o tema das diversas formas de discriminação, cabe lembrar que apenas a discussão não parece uma medida suficiente quando uma pessoa é atacada pela discriminação. As advertências são necessárias e propõe-se que deva ser avaliada a gravidade de cada caso pois mesmo as advertências verbais podem não ser suficientes dependendo do impacto e da agressão da pessoa que discrimina a orientação sexual de outrem. 
Ainda que a Petrobrás não tenha comunicado, com consistência, suas ações pró-diversidade sexual nos documentos analisados ou não possua as melhores práticas possíveis no que tange tal diversidade, (especialmente ao comparar com os critérios internacionais de igualdade corporativa), pode-se constatar que, pelo menos, ela possui algumas ações ou políticas que abordem a diversidade por orientação sexual. Isto significa que, ao considerar a realidade de outras empresas situadas no Brasil - que na maior parte das vezes possuem a política do total silêncio público a tais questões - pode-se extrair das ações comunicadas nos relatórios da Petrobrás boas práticas no contexto nacional que podem inspirar outras empresas que desejem adotar tais iniciativas.

Para empresas e lideranças com uma preocupação ainda maior com a questão da diversidade sexual, isto é, para além do que a Petrobrás realiza, vale lembrar que, além de seus acertos e boas práticas, os critérios do Corporate Equality Index podem ser ainda mais inspiradores, assim como podem ser relevantes as sugestões de melhoria dos pontos fracos da Petrobrás oferecidas nesta conclusão. Se há empresas que conseguem atingir a pontuação máxima do Corporate Equality Index no exterior, é importante que as empresas e lideranças nacionais que realmente desejarem tratar seus trabalhadores(as) LGBTs com dignidade e igualdade de direitos trabalhem tendo este norte como direção de suas ações.

\section{Referências}

BARDIN, L. Análise de conteúdo. Lisboa: Edições 70, 1977.

CHRISTENSEN, L.T. Corporate communication: the challenge of transparency. Corporate communications: an international journal, v. 7, n. 3, p. 162-168, 2002.

;CORNELISSEN, J. Bridging corporate and organizational communication: review, development and a look to the future. Management communication quarterly, v. 25, n. 3, p. 383-414, 2011.

; LANGER, R. Public relations and the strategic use of transparency: consistency, hypocrisy and corporate change. In TOTH, Elizabeth L.; HEAT, Robert L. (Eds.). Critical and rhetorical approaches to public relations. Hillsdale, NJ: Lawrence Erlbaum, 2009. p.129-153. ; FIRAT, A. F.; TORP, S. The organization of integrated communications: toward flexible integration.

European journal of marketing, v. 42, n. 3/4, p. 423-452, 2008. et al. Ethics, CSR, and sustainability education in the Financial Times Top 50 global business schools: 
baseline data and future research directions. Journal of business ethics, v. 73, n. 4, p. 347-368, 2007.

FROST, P. J. Power, politics and influence. In: JABLIN, F. et al. (Eds.). Handbook of organizational conversation: an interdisciplinary perspective: 503-548. Newbury Park, CA: Sage, 1987.

HRC, HUMAN RIGHTS CAMPAIGN. Corporate equality index. Washington, D.C.: Human Rights Campaign, 2013. Disponível em <http://www.hrc.org/files/assets/resources/CorporateEqualitylndex_2013.pdf>.Acesso em: 17 out. 2013.

The HRC story: about us. Disponível em <http://www.hrc.org/the-hrc-story/about-us>. Acesso em: 29 jan. 2015 a.

The HRC story: HRC Foundation. Disponível em <http://www.hrc.org/the-hrc-story/hrc-foundation>. Acesso em: 30 jan. 2015b.

MARREWIJK, M. Concepts and definitions of CSR and corporate sustainbility: between agency and communion. Journal of business ethics, v. 44, n. 2, p. 95-105, may. 2003.

MECCHI, C. L. Diversidade sexual e políticas de gestão de pessoas: um estudo exploratório em três empresas de grande porte. 2006. Trabalho de Conclusão de Curso (Graduação em Administração)- Faculdade de Economia, Administração e Contabilidade, Universidade de São Paulo, São Paulo, 2006.

PETROBRAS. Código de ética do sistema Petrobrás. Rio de Janeiro: Petrobras, [2006]. Disponível em <http://www.investidorpetrobras.com.br/download/465>. Acesso em: 09 out. 2014.

. Memória cultural 2000-2008: festival Mix Brasil de cinema e vídeo da diversidade sexual. Rio de Janeiro: Petrobras, 2009. Disponível em <http://sites.petrobras.com.br/minisite/memoriacultural/port/ cinema/FestivalMix11.asp>. Acesso em: 11 out. 2014.

Programa Petrobrás cultural 2006/2007: projetos contemplados. Rio de Janeiro: Petrobras, 2006. Disponível em <http://ppc.petrobras.com.br/sites/default/files/documentos/resultados_2006-2007.pdf>. Acesso em: 10 out. 2014.

. Programa Petrobrás cultural 2007/2008: projetos contemplados. Rio de Janeiro: Petrobras, 2007.

Disponível em <http://ppc.petrobras.com.br/sites/default/files/documentos/resultados-2007-2008.pdf>. Acesso em: 10 out. 2014.

. Relatório de sustentabilidade 2013. Rio de Janeiro: Petrobras, 2014. Disponível em < http:// www.investidorpetrobras.com.br/download/1158>. Acesso em: 09 out. 2014.

Relatório de sustentabilidade 2012. Rio de Janeiro: Petrobras, 2013. Disponível em < http:// www.investidorpetrobras.com.br/download/1162>. Acesso em: 09 out. 2014.

. Relatório de sustentabilidade 2011. Rio de Janeiro: Petrobras, 2012. Disponível em <http://www. investidorpetrobras.com.br/download/1210>. Acesso em: 09 out. 2014.

Relatório de sustentabilidade 2010. Rio de Janeiro: Petrobras, 2011a. Disponível em <http:// 
www.investidorpetrobras.com.br/download/1218>. Acesso em: 09 out. 2014.

. Relatório de sustentabilidade 2009. Rio de Janeiro: Petrobras, 2010. Disponível em <http://www. investidorpetrobras.com.br/download/1230>. Acesso em: 09 out. 2014.

Transparência pública: contratos de serviços. Rio de Janeiro: Petrobras, 2011b. Disponível em <http://sites.petrobras.com.br/minisite/acessoainformacao/materiaishtm/contratos_servicos/ PORTAL_1000_S/Documents/index.htm>. Acesso em: 12 out. 2014.

PUTNAM, L. L.; NICOTERA, A. M. Building theories of organization: the constitutive role of communication. London, UK: Routledge, 2009.

Communicative constitution of organization is a question: critical issues for addressing it. Management communication quarterly, v. 24, n. 1, p. 158-165, 2010.

SIQUEIRA, M. V. S.; ZAULI-FELLOWS, A. Diversidade e identidade gay nas organizações. Revista eletrônica de gestão organizacional, v. 4, n. 3, p. 69-81, 2006.

WEICK, K. E. Theorizing about organizational communication. In: JABLIN, F. et al. (Eds.). Handbook of organizational conversation: an interdisciplinary perspective: 503-548. Newbury Park, CA: Sage, 1987. p. 97-122. 